\title{
A cluster-randomized controlled trial of handrubs for prevention of infectious diseases among children in Colombia
}

\author{
Juan C. Correa, ${ }^{1}$ Diana Pinto, ${ }^{2}$ Lucas A. Salas, ${ }^{1}$ Juan C. Camacho, ${ }^{1}$ \\ Martín Rondón, ${ }^{3}$ and Juliana Quintero ${ }^{4}$
}

Suggested citation Correa JC, Pinto D, Salas LA, Camacho JC, Rondón M, Quintero J. A cluster-randomized controlled trial of handrubs for prevention of infectious diseases among children in Colombia. Rev Panam Salud Publica. 2012;31(6):476-84.

ABSTRACT Objective. To evaluate the effectiveness of alcohol-based handrubs $(A B H)$ in reducing acute diarrheal diseases $(A D D)$ and acute respiratory infections (ARI) among children 1-5 years of age in childcare centers with limited tap water.

Methods. This was the first cluster-randomized controlled trial in a developing country. The study took place at 42 childcare centers with sporadic and limited water availability in six towns in Colombia. Participants were randomly assigned to use ABH as a complement to handwashing (intervention arm: 21 centers/794 children); or to continue existing handwashing practices (control arm: 21 centers/933 children). ADD and ARI cases were identified through teacher-reported signs and symptoms of illness. Adverse events were monitored. Hazard ratios (HR) were obtained using Cox proportional hazards multivariate regression shared frailty models.

Results. Child-days of surveillance totaled 336 038. Loss to follow up was 14.5\%. For both $A D D$ and $A R I$, there were no differences in hazard ratios during the first trimester of the study. In the second and third trimesters, significant reductions in the risk of ADD were found in the intervention compared to control arm $(\mathrm{HR}=0.55, \mathrm{P}<0.001$ and $\mathrm{HR}=0.44$, $\mathrm{P}<0.001$, respectively). There were also significant risk reductions for ARI in the second trimester $(\mathrm{HR}=0.80, \mathrm{P}<0.05)$ and in the third trimester $(\mathrm{HR}=0.69, \mathrm{P}<0.001)$. No adverse events occurred.

Conclusions. ABH effectively prevent ADD and ARI, and are safe. Colombia's national public health policies for prevention of these diseases should include use of $A B H$, especially in settings where handwashing with soap and water is limited by water availability.

Trial registration. Clinical Trials.gov ID: NCT00963391.

Key words Handwashing; anti-infective agents, local; gastrointestinal diseases; respiratory tract infections; diarrhea; ethanol; child, preschool; developing countries; randomized controlled trials as topic; Colombia.

División de Salud Comunitaria, Fundación Santa Fe de Bogotá, Bogotá, Colombia. Send correspondence to Juan C. Correa, jccorrea47@gmail.com

2 Fedesarrollo, Bogotá, Colombia.

3 Departamento de Epidemiología Clínica y Bioestadística, Pontificia Universidad Javeriana, Bogotá, Colombia.

4 Centro de Estudios e Investigaciones en Salud, Fundación Santa Fe de Bogotá, Bogotá, Colombia.
In the developing world, acute diarrheal disease (ADD) and acute respiratory infection (ARI) are leading causes of morbidity and mortality in children under 5 years of age (1). ARI contributed 67 million disability adjusted life years (DALYs) to the global burden of disease in 2000, and ADD, another 45 million (2). In Colombia, these diseases ranked among the first five causes of DALYs in the 0-4 year age group (3). Increased efforts to prevent and control 
these diseases are needed to achieve the Millennium Development Goal of reducing under- 5 child mortality rates by two-thirds (4).

Hands are one of the most important transmission routes for ADD and ARI (5, 6). Handwashing with soap and water (HSW) is a key practice in preventing these illnesses $(7,8)$. Unfortunately, a large proportion of the population burdened by these diseases lives in places where water is either a scarce natural resource or availability is limited by infrastructure deficiencies $(9,10)$. Therefore, identifying hand hygiene $(\mathrm{HH})$ alternatives for these scenarios is a priority.

The practicality of HSW in highdemand settings, such as schools, poses barriers to $\mathrm{HH}$. In Bogotá, Colombia, a study of determinants of $\mathrm{HH}$ behavior of 6th-8th grade students in 25 schools found that less than one-third of the students practiced $\mathrm{HH}$ recommendations, and adoption of HSW was affected by irregular availability of soap and proper functioning of hand sinks (11). In the health care community, where $\mathrm{HH}$ is recognized as essential for infection prevention, international literature has shown that failure to adhere to $\mathrm{HH}$ guidelines is common, requiring adoption of a wide array of strategies to improve compliance (12).

Alcohol-based handrubs $(\mathrm{ABH})$ could be an option for the above situations. Intervention studies examining the impact of $\mathrm{ABH}$ with and without HSW have been conducted in North America and Europe. Although positive effects were found, methodological shortcomings of these studies preclude conclusions about the effectiveness of $\mathrm{ABH}(5,13) . \mathrm{ABH}$ have not been tested as a strategy for $\mathrm{HH}$ in developing countries, though there is evidence of their efficacy in reducing microbiological burden in secondary schools and in community settings in Africa and Asia (14-15). The study objective was to evaluate the effectiveness of $\mathrm{ABH}$ availability and training in its use on ADD and ARI incidence among children 1-5 years of age in childcare centers with limited tap water.

\section{METHODS}

\section{Study design}

A cluster-randomized control trial was conducted in childcare centers in six ur- ban settings in Colombia. The study protocol was approved by the Institutional Review Board of the Fundación Santa Fe de Bogotá, Code No. 00008353 (Bogotá, Colombia). The protocol included a pilot study conducted in two childcare centers during 2007 to field test the study instruments adapted from previous work (13, 16), to test trial procedures, and to obtain estimates for sample size parameters. No pilot centers participated in the trial.

\section{Participants}

Eligible childcare centers were either "community homes" or preschools licensed to care for 12 or more children 1-5 years of age for 8 hours a day, 5 times per week, and where availability of tap water was limited. Limited tap water availability was defined as interruptions in water provision lasting 24 hours or more at least once a week, or lasting several hours per day every day. "Community homes" were homes of local caregivers trained in basic childcare, where a maximum of 14 children spend the day in a dedicated room with a bathroom, often without a hand sink. Preschools have two to eight age-specific classrooms (maximum 32 children) overseen by teachers with formal training. These facilities had one or more bathrooms with hand sinks that were often non-functioning.

A total of 46 eligible centers were identified in 2007 by administering an $\mathrm{HH}$ infrastructure and practices survey to all 82 institutions listed in the official preschool database of Bogotá and five neighboring towns: Anapoima, Espinal, La Mesa, Melgar, and Soacha. Within centers, eligible children were those 1-5 years of age as of January 2008, with no previous history of chronic illness predisposing to infectious disease.

Recruitment of trial participants began in January 2008. Approval to conduct the trial was obtained from the respective national and local education authorities. Agreement to participate was requested from center directors during an introductory meeting conducted with all center staff during which trial procedures were explained and general information about HH (germ theory, hand washing technique, and key $\mathrm{HH}$ moments) was provided. Each parent/guardian was contacted through the childcare center and informed-consent for the child's participation was requested. A baseline survey of child and household risk factors for ADD and ARI was administered to the principal caregiver.

\section{Intervention}

The trial ran from 16 April to 18 December 2008. For centers assigned to the intervention arm, $\mathrm{ABH}$ and training on proper use were provided to staff and children. One $\mathrm{ABH}$ dispenser was installed in each center with fewer than 14 children; in larger centers, one dispenser was installed per classroom, plus an additional one for common areas in those centers with more than 28 children. Dispensers were refilled continuously throughout the trial with ethanol $62.0 \%$ (Purell ${ }^{\circledR}$, GOJO Industries, Akron, Ohio, United States), which was chosen because it has been used in other community interventions and is available in Colombia. Proper use of $\mathrm{ABH}$ was ensured by: (i) a pre-trial $\mathrm{ABH}$ use workshop that followed recommended $\mathrm{HH}$ teaching techniques $(6,8,17-20)$ and instructed teachers to add $\mathrm{ABH}$ to routine $\mathrm{HH}$ and give preference to HSW if hands were visibly soiled; (ii) location of visual reminders on $\mathrm{ABH}$ technique in bathrooms and next to dispensers; and (iii) provision of monthly 30-minute $\mathrm{ABH}$ technique refresher workshops (eight per center).

Prior to trial initiation, skin sensitivity tests for $\mathrm{ABH}$ were applied to all staff and children. Adverse reactions were monitored and upon suspicion, children were examined by a physician. Safety conditions, proper use of each dispenser, and amount of $\mathrm{ABH}$ used were monitored bi-weekly. The amount of $\mathrm{ABH}$ used was quantified by recording the volume supplied to each center.

Centers assigned to the control arm were simply told to continue their current practices; placebo was not provided as it would be unethical to use an inactive $\mathrm{HH}$ product.

\section{Sample size}

Target sample sizes of 147 children per ADD arm and 62 children per ARI arm were determined based on requiring $80 \%$ power to detect a $30 \%$ reduction in ADD and ARI based on incidence densities observed during the pilot study (1.23 ADD and 2.91 ARI cases per childyear). A test of $5.0 \%$ significance level 
was used. The sample size was adjusted by a factor of 1.65 , based on a value of 0.05 for the intra-cluster correlation (ICC) coefficient $(21,22)$ for 42 clusters of median size 14 children (23-26). Anticipating $20 \%$ losses to follow-up, the required clustered sample for a 9-month (300 day) observation period was 243 children per arm (72 900 child-days) for ADD, and 103 children per arm (30 900 child-days) for ARI, equivalent to 21 clusters of 14 children each per arm (88 200 child-days).

\section{Randomization}

Figure 1 illustrates the randomization procedure. First, study arms were balanced with respect to variables available from the baseline survey, which $a$ priori were considered to be associated with study outcomes. The balancing procedure grouped centers in sequential order by type of center (community or preschool), geographic location, center characteristics (number of children, water source, water availability, functioning sink, water chlorination, percentage of mothers with more than a primary education, percentage of children with complete immunization scheme), and household water source and availability. Four centers were excluded due to large differences in their baseline characteristics. The remaining 42 centers were distributed in 12 groups. Second, using the random function in Microsoft Excel ${ }^{\mathrm{TM}}$ (Microsoft Corp., Redmond, Washington, United States), random numbers (1 or 2) were generated and allotted 1:1 within each group. Finally, a researcher flipped a coin to decide which number would correspond to either arm (heads = 1 , intervention; tails $=2$, control).

\section{Outcomes}

Primary outcome measures were new cases of ADD and ARI. Case definitions were based on previous studies (21, 22) and opinion of experts in pediatrics and epidemiology. ADD was defined as three or more loose stools per day, lasting 24 hours or more. ARI was defined as two or more of the following symptoms for at least 24 hours, lasting at least 2 days: runny, stuffy, or blocked nose or noisy breathing; cough; fever, hot sensation, or chills; and/or sore throat. Ear pain alone was considered ARI. Alter-

FIGURE 1. Flow diagram of balancing procedure used to group childcare centers by selected variables and subsequent allocation to the intervention or control arm for study of alcohol-based handrubs in prevention of acute diarrhea and acute respiratory infections, Colombia, 2008

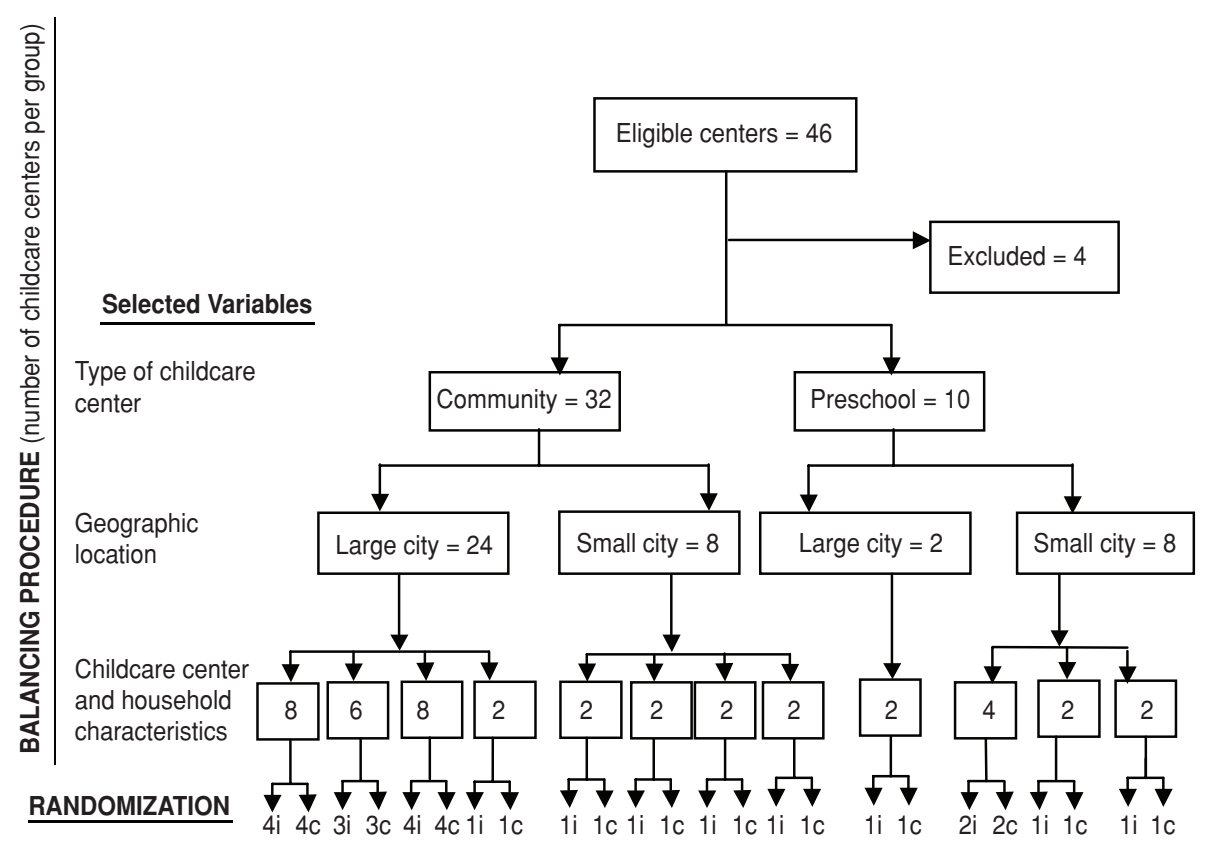

(Number of centers allocated to $i=$ intevention and $c=$ control)

Note: Geographic location: six urban areas (Anapoima, Bogotá, Espinal, La Mesa, Melgar, and Soacha).

nately, if a parent provided a physician's certification of ADD or ARI diagnosis it qualified as a case. All cases of ADD and ARI were registered and included in the analyses. A new event was defined as an episode occurring 48 hours after a symptom-free period.

A secondary outcome measure was incidence of adverse events, such as skin reactions defined as redness and/or desquamation or dryness of hand skin using the Visual Skin Score (VSS) as reported by Grove (27), or accidental ingestion. The outcome observation and intervention phases were contemporaneous.

\section{Procedures}

Prior to the trial, teachers in both arms received training in case registry. They were instructed to identify signs of ADD or ARI through direct observation, or by asking parents/guardians about signs and symptoms of ADD or ARI as a reason for absenteeism. For each possible case, teachers completed a standard checklist that inquired about presence, onset, and duration of ADD and ARI signs and symptoms. Because it was not possible to blind teachers to arm assignment, reduction of ascertainment bias was sought by not providing case definitions. Case registry formats were reviewed by the project coordinator (a physician blinded to study arms), who decided if case criteria were met. Doubts were clarified with teachers and, if necessary, children were examined. Case registry was supervised through phone calls and bi-weekly on-site visits, during which potential cases (children with runny noses, frequent visits to the toilet) observed by the supervisor were cross-checked with registries. Teachers received a fixed, modest economic compensation for time spent on case reporting, independent of the number of completed formats.

The study also explored teachers' perceptions about changes in $\mathrm{HH}$ practices and use of HSW and $\mathrm{ABH}$ during trial implementation by applying a semi-structured survey at trial completion. Consumption of resources and costs related to $\mathrm{ABH}$ use and HSW were also quantified. Results are available upon request.

\section{Statistical analysis}

All enrolled centers and children were included in the analyses on an intention- 
to-treat basis. For children lost to follow up, data from the last available contact was included.

Incidence densities for ADD and ARI were calculated as number of new cases divided by number of susceptible childdays at risk. To compare infection rates by arm, a shared frailty model was selected: this is a Cox proportional hazards regression for recurrent events in which an unobserved gamma-distributed random factor, called frailty, is introduced at the individual (child) level to account for clustering, event dependence, and unobserved heterogeneity in ADD and ARI risk factors (28-33). Initial models included baseline covariates considered to be risk factors for ADD and ARI: gender, insurance status, complete immunization scheme, crowding, household water piping frequency, pets, household $\mathrm{HH}$ practices, and baseline prevalence of ADD or ARI. Follow-up trimester was included as a covariate to address variation in length of exposure to $\mathrm{ABH}$ and seasonal risk factors, and as an interaction term with study arm to estimate time-dependent differential effects of the intervention. A backward selection strategy determined the final multivariate model, which included age, intensity of $\mathrm{ABH}$ use, and trimester. The ADD model also controlled for an episode of ADD two weeks prior to baseline. Effect measures were expressed as hazard ratios. Significance of child-level frailty term was tested by the likelihood ratio or theta, which confirmed presence of heterogeneity. Analyses were performed using Stata ${ }^{\circledR} /$ MP11 (StataCorp LP, College Station, Texas, United States).

\section{RESULTS}

\section{Participant flow}

A detailed description of participant flow is provided in Figure 2. Fourty-two centers (1 727 children) were randomized, 21 per arm (control $n=933$, intervention $n=794$ ). During implementation, $14.5 \%$ of participants (250 children) withdrew from the centers. Two centers (one per arm) were closed because teachers resigned; therefore, 19 children were relocated to other study centers and classified as lost to follow-up. After trial onset, 372 new children entered trial centers (control $n=229$, intervention $n=143$ ). No significant differences were evident between the characteristics of children

FIGURE 2. Flow diagram of enrollment, randomization, and follow up in a study of alcohol-based handrubs for prevention of acute diarrhea and acute respiratory infections, Colombia, 2008

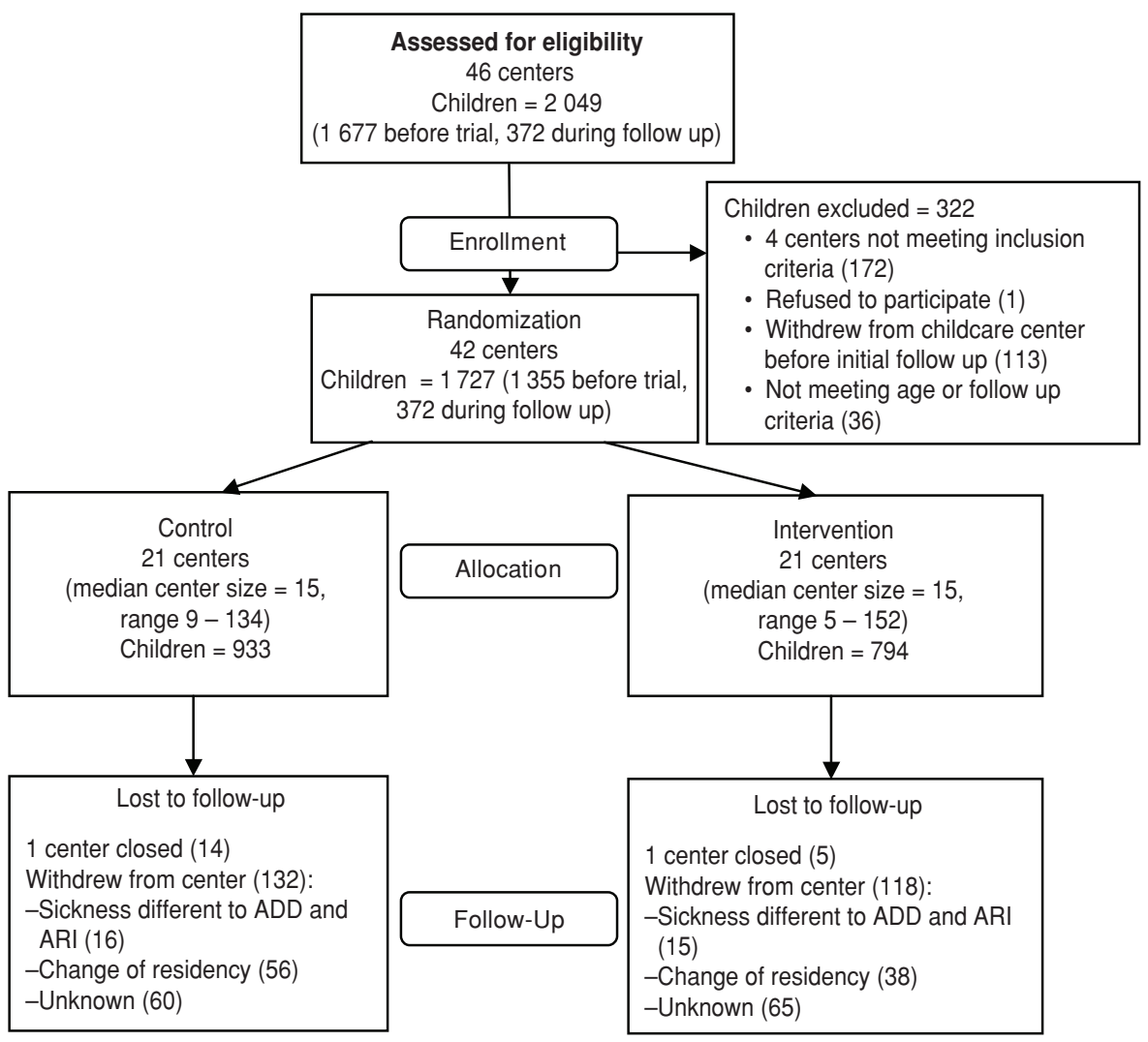

TABLE 1. Baseline infrastructure characteristics of child care centers included in the study of alcohol-based handrubs for prevention of acute diarrhea and acute respiratory infections, Colombia, 2008

\begin{tabular}{|c|c|c|c|c|c|}
\hline \multirow[b]{2}{*}{ Characteristic } & \multicolumn{2}{|c|}{$\begin{array}{l}\text { Control arm } \\
\qquad(n=21)\end{array}$} & \multicolumn{2}{|c|}{$\begin{array}{l}\text { Intervention arm } \\
\qquad(n=21)\end{array}$} & \multirow[b]{2}{*}{$P$ value ${ }^{a}$} \\
\hline & No. & $\%$ & No. & $\%$ & \\
\hline Childcare center (size $\leq 28$ children) & 16 & 76.2 & 16 & 76.2 & 1.0000 \\
\hline Aqueduct as water source ${ }^{b}$ & 8 & 38.1 & 8 & 38.1 & 1.0000 \\
\hline \multicolumn{6}{|l|}{ Water supply frequency } \\
\hline Daily, some hours & 2 & 9.5 & 0 & 0.0 & 0.1473 \\
\hline Every 24 hours & 5 & 23.8 & 4 & 19.0 & 0.7069 \\
\hline Every 48 hours & 9 & 42.9 & 8 & 38.1 & 0.7532 \\
\hline 3-4 times per week & 5 & 23.8 & 9 & 42.9 & 0.1904 \\
\hline Functioning sink ${ }^{c}$ & 10 & 47.6 & 8 & 38.1 & 0.5329 \\
\hline Protected water storage ${ }^{d}$ & 19 & 90.5 & 18 & 85.7 & 0.6337 \\
\hline
\end{tabular}

$\chi^{2}$ test for difference in proportions.

b Defined as a treated (chlorinated) water source distributed by formal sanitary infrastructure.

c Defined as a basin with running water and proper water drainage.

${ }^{d}$ Defined as use of measures to avoid contamination of water if storage is needed (i.e., covered vessels).

who were lost to follow-up and those who completed the study.

\section{Baseline characteristics of centers, children, and households}

Data from the center facility survey showed no differences in $\mathrm{HH}$ infrastruc- ture between control and intervention centers (Table 1).

Baseline child demographic and health characteristics were similar in study arms (Table 2), except for gender, insurance status, complete immunization scheme, and reporting an episode of ADD two weeks prior to trial onset. Baseline house- 
TABLE 2. Baseline sociodemographic and health characteristics of children included in study of alcohol-based handrubs for prevention of acute diarrhea disease (ADD) and acute respiratory infections (ARI), Colombia, 2008

\begin{tabular}{|c|c|c|c|c|c|}
\hline \multirow[b]{2}{*}{ Characteristic } & \multicolumn{2}{|c|}{$\begin{array}{l}\text { Control arm } \\
(n=933)\end{array}$} & \multicolumn{2}{|c|}{$\begin{array}{l}\text { Intervention arm } \\
\quad(n=794)\end{array}$} & \multirow[b]{2}{*}{$P$ value ${ }^{\mathrm{a}}$} \\
\hline & No. & $\%$ & No. & $\%$ & \\
\hline Age in years, mean (SD) & 3.23 & 1.0 & 3.23 & 1.0 & $1.0000^{\mathrm{b}}$ \\
\hline $1-2$ & 117 & 12.5 & 108 & 13.6 & 0.0233 \\
\hline$>2-3$ & 253 & 27.1 & 218 & 27.5 & 0.3916 \\
\hline$>3-4$ & 325 & 34.8 & 258 & 32.5 & 0.9884 \\
\hline$>4-5$ & 226 & 24.2 & 197 & 24.8 & 0.5136 \\
\hline$>5$ & 12 & 1.3 & 13 & 1.6 & 0.5246 \\
\hline Female & 454 & 48.7 & 343 & 43.0 & 0.0233 \\
\hline Mother's educational level: elementary school or less & 240 & 25.7 & 204 & 25.7 & 0.9884 \\
\hline Mother's age in years, mean (SD) & (27.97) & 6.97 & (27.88) & 6.53 & 0.3916 \\
\hline Insurance: Contributory or other & 285 & 30.6 & 291 & 36.7 & 0.0073 \\
\hline Insurance: subsidized & 388 & 41.6 & 285 & 35.9 & 0.0156 \\
\hline Uninsured & 231 & 24.8 & 199 & 25.1 & 0.8842 \\
\hline Full term delivery & 780 & 83.6 & 642 & 80.9 & 0.1360 \\
\hline Last year's perceived health status "excellent" or "good" & 715 & 76.6 & 614 & 77.3 & 0.7323 \\
\hline Complete immunization scheme & 760 & 81.5 & 692 & 87.2 & 0.0013 \\
\hline Episode of ADD two weeks before baseline & 150 & 16.1 & 98 & 12.3 & 0.0274 \\
\hline Episode of ARI two weeks before baseline & 376 & 40.3 & 310 & 39.0 & 0.5946 \\
\hline Forcefully displaced ${ }^{c}$ & 29 & 3.1 & 19 & 2.4 & 0.3675 \\
\hline
\end{tabular}

a F-test for differences in means, adjusted for cluster effect.

${ }^{b}$ Likelihood ratio test for difference in probabilities, adjusted for cluster effect.

${ }^{c}$ Violence related displacement.

TABLE 3. Housing and hygiene practices characteristics among households of children included study of alcohol-based handrubs for prevention of acute diarrhea disease (ADD) and acute respiratory infections (ARI), Colombia, 2008

\begin{tabular}{|c|c|c|c|c|c|}
\hline \multirow[b]{2}{*}{ Characteristic } & \multicolumn{2}{|c|}{$\begin{array}{l}\text { Control arm } \\
n=933\end{array}$} & \multicolumn{2}{|c|}{$\begin{array}{l}\text { Intervention arm } \\
\quad n=794\end{array}$} & \multirow[b]{2}{*}{$P$ value ${ }^{a}$} \\
\hline & No. & $\%$ & No. & $\%$ & \\
\hline Type of housing: House or apartment & 742 & 79.5 & 613 & 77.2 & 0.2416 \\
\hline Crowding (more than 3 persons per room) & 67 & 7.2 & 37 & 4.7 & 0.0282 \\
\hline Presence of children under 5 in the household & 386 & 41.4 & 341 & 43.0 & 0.5087 \\
\hline \multicolumn{6}{|l|}{ Community tank as household main water } \\
\hline source $^{b}$ & 924 & 99.0 & 780 & 98.2 & 0.1491 \\
\hline Frequency of water piping (hours per week), mean (SD) & $(86.88)$ & 70.7 & (105.33) & 71.9 & $<0.0001$ \\
\hline Use of any practice to improve water qualityc ${ }^{c}$ & 717 & 76.9 & 634 & 79.9 & 0.1322 \\
\hline Functioning sink & 755 & 80.9 & 645 & 82.3 & 0.8688 \\
\hline Functioning toilet & 690 & 73.9 & 566 & 71.6 & 0.2143 \\
\hline Smoking & 201 & 21.5 & 166 & 20.9 & 0.7472 \\
\hline Owns a dog or cat & 323 & 34.6 & 319 & 40.2 & 0.0172 \\
\hline More frequent HWS if someone in household has ARI & 444 & 47.6 & 416 & 52.4 & 0.0466 \\
\hline More frequent HWS if someone in household has ADD & 602 & 64.5 & 547 & 68.9 & 0.0552 \\
\hline
\end{tabular}

HWS: handwashing with soap and water.

a Likelihood ratio test for difference in probabilities, adjusted for cluster effect.

b Community tank is a reservoir in which water is collected and distributed through plastic pipes.

c Use of measures to improve water quality such as boiling or filtering before consumption.

hold characteristics are shown in Table 3. Differences in favor of the intervention arm were observed with respect to crowding, total hours of water supply, using stored water for cooking, frequency of water reservoir cleaning, and increased hand washing when a household member had either ADD or ARI. More households in the intervention arm reported having a dog or a cat.

\section{$\mathrm{HH}$ practices, $\mathrm{ABH}$ use, and adverse events}

Seventy-six percent $(n=34)$ of intervention center teachers and $83 \%(n=$ 32) of control center teachers were surveyed about their $\mathrm{HH}$ practices before and after the trial. Teachers at seven of the intervention centers reported almost complete substitution of HSW for
$\mathrm{ABH}$ application and reported HSW decreased from a median of 3 times daily at trial onset, to once daily at the end, while final median $\mathrm{ABH}$ application rose to 6 times per day. Use of HSW was left for situations where hands were visibly contaminated with soil or food, or after tooth brushing. In the remaining 14 intervention centers, teachers complemented HSW practices with gel application (partial substitution), which resulted in an overall increase in $\mathrm{HH}$ opportunities. Use of $\mathrm{ABH}$ was perceived by all intervention center teachers as a more convenient $\mathrm{HH}$ method and manifested willingness to continue its use. Median reported HSW frequency at trial end in control centers was 3 times daily. No changes in $\mathrm{HH}$ practices were reported.

Quantification of $\mathrm{ABH}$ consumption adjusted for daily attendance confirms the reported increase in its use. From start to end of trial, quantified median number of applications per child rose from 3.5 to 4.5 in preschools and from 3.5 to 5.5 in community centers (Figure 3 ). No adverse events were observed.

\section{Crude, unadjusted incidence densities}

The incidence density of ADD was 0.75 per child-year (693 episodes during 336038 child-days of observation). Incidence density of ADD in the intervention arm was 0.61 per child-year, (259 episodes during 154959 child-days of observation) and in the control arm 0.88 per child-year (434 episodes during 181079 child-days of observation), $P<$ 0.0001. The calculated ICC was 0.004 .

The incidence density of ARI was 2.18 per child-year (2 008 episodes during 336038 child-days of observation). Incidence density of ARI in the intervention arm was 2.06 per child-year, (873 episodes during 154959 child-days of observation) and in the control arm 2.28 per child-year (1 135 episodes during 181079 child-days of observation), $P=$ 0.0163 . The calculated ICC was 0.01 .

\section{Adjusted effect of $\mathrm{ABH}$ on ADD and ARI incidence}

Adjusted estimates of the effect $\mathrm{ABH}$ availability on the risk of ADD and ARI in intervention centers compared to controls are presented in Table 4. For both diseases, hazard ratios did not differ during the first trimester of the trial. However, after this period, hazard ratios 
FIGURE 3. Trend in median handrub pushes per child per day during the follow-up period by child care center type in study of alcohol-based handrubs (ABH) for prevention of acute diarrhea and acute respiratory infections, Colombia, 2008
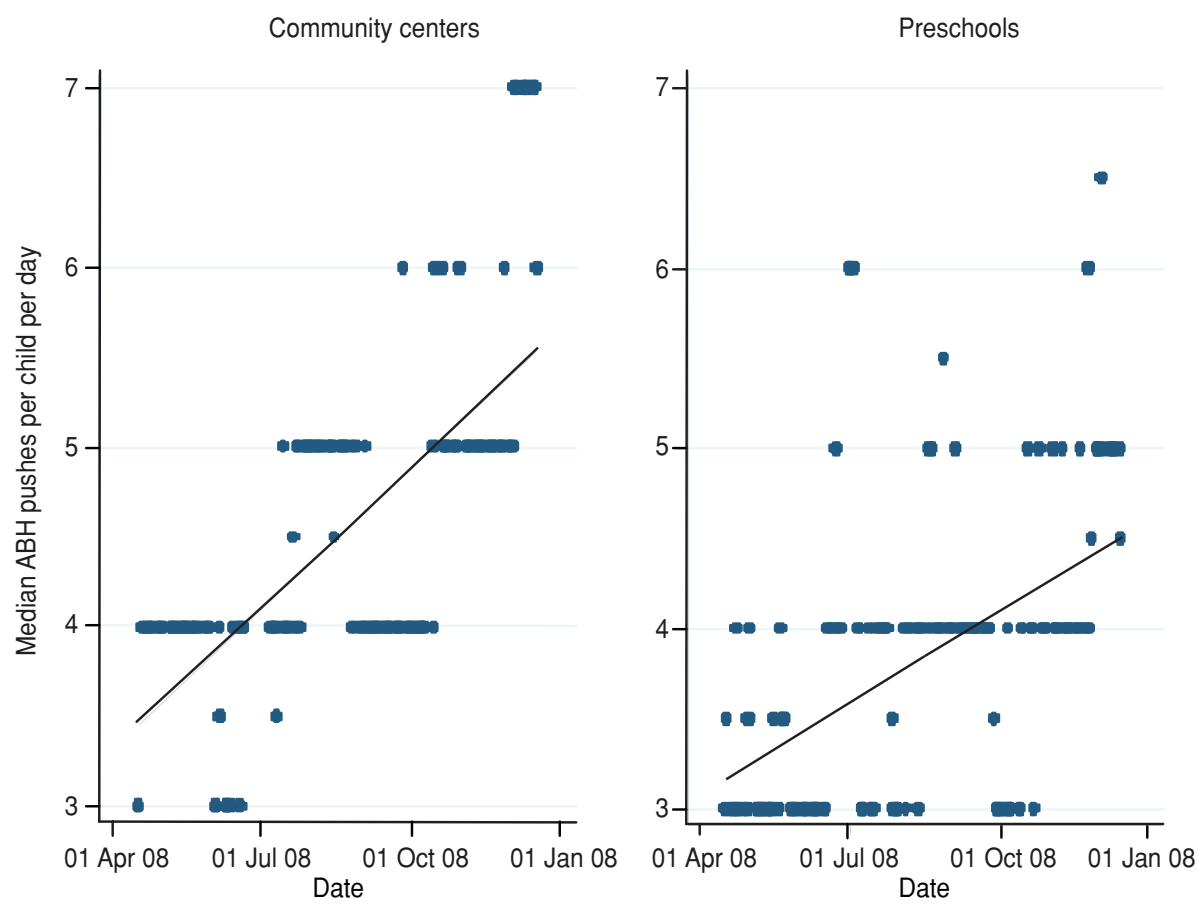

Note: Median ABH pushes per child were calculated based on total volume of gel used per day adjusted for child attendance. According to the manufacturer information, every push/application is equivalent to $0.6 \mathrm{cc}$ (1666 pushes per liter pack).

TABLE 4. Adjusted effect of availability of alcohol-based handrubs on the risk of acute diarrheal disease (ADD) and acute respiratory infections (ARI) by trial implementation trimester, age group, and previous disease among childcare centers allocated to the intervention arm, compared to the control arm, Colombia, 2008

\begin{tabular}{|c|c|c|c|c|}
\hline \multirow[b]{2}{*}{ Category $^{a}$} & \multicolumn{2}{|c|}{ ADD model ${ }^{b}$} & \multicolumn{2}{|c|}{ ARI modelc } \\
\hline & Hazard ratio & $95 \% \mathrm{Cl}$ & Hazard ratio & $95 \% \mathrm{Cl}$ \\
\hline Trial implementation trimester 1 & 0.84 & $0.61-1.15$ & 0.93 & $0.79-1.10$ \\
\hline Trial implementation trimester 2 & $0.55^{d}$ & $0.42-0.73$ & $0.80^{\mathrm{e}}$ & $0.68-0.94$ \\
\hline Trial implementation trimester 3 & $0.44^{\mathrm{d}}$ & $0.31-0.61$ & $0.69^{d}$ & $0.57-0.83$ \\
\hline 2 years of age vs. 1 year & $0.35^{d}$ & $0.26-0.48$ & $0.79 \mathrm{e}$ & $0.66-0.96$ \\
\hline 3 years of age vs. 1 year & $0.26^{d}$ & $0.19-0.36$ & $0.65^{d}$ & $0.54-0.79$ \\
\hline 4 years of age vs. 1 year & $0.25^{d}$ & $0.18-0.35$ & $0.61^{d}$ & $0.50-0.74$ \\
\hline 5 years of age vs. 1 year & 0.44 & $0.17-1.14$ & 0.62 & $0.33-1.19$ \\
\hline Episode of ADD 2 weeks prior to baseline & $1.74^{d}$ & $1.34-2.26$ & - & - \\
\hline Theta & $1.57^{d}$ & & $0.54^{d}$ & \\
\hline
\end{tabular}

Note: Coefficients are exponentiated.

a The reference category is the control group.

${ }^{b}$ ADD model adjusted by sex, insurance, substitution of handwashing with soap and water (HSW) for alcohol-based handrubs $(\mathrm{ABH})$ application, complete immunization scheme, episode of ADD 2 weeks before baseline. Includes intervention-trimester interaction term.

${ }^{c} \mathrm{ARI}$ model adjusted by sex, insurance, substitution of HSW for ABH application, complete immunization scheme. Includes intervention-trimester interaction term.

d $P<0.001$.

e $P<0.05$.

favor the intervention arm. Significant reductions in risk of ADD in the intervention arm compared to control arm were found during the trial's second and third trimesters: $H R=0.55, P<0.001$, and $H R=0.44, P<0.001$, respectively.
For ARI, significant reductions in risk were also in the second and third trimesters: $H R=0.80, P<0.05$, and $H R=0.69$, $P<0.001$, respectively. Children 2-4 years of age were found to have a lower risk of disease compared to those 1 year of age. Having had a previous episode of ADD in the 15 days before baseline measurement increased the risk of this disease.

\section{DISCUSSION}

This is the first CRCT trial to provide evidence supporting the potential role of $\mathrm{ABH}$ in reducing ADD and ARI incidence in childcare settings in a middleincome country. Reduction of risk of ADD and ARI was found in childcare centers that had $\mathrm{ABH}$ available versus only HSW, and this reduction increased with duration of trial implementation. The direction and order of magnitude ${ }^{5}$ of these findings is consistent with the results of intervention studies in developed countries that have examined the effect of $\mathrm{ABH}$ use and training on infectious diseases (34). Values of pooled estimates of rate ratios from meta-analyses of these studies are 0.77 for gastrointestinal illness (95\% CI $=0.52-1.13)$ and 0.93 for respiratory illness $(95 \% \mathrm{CI}=$ 0.84-1.03), though for both cases the CI included the null value (35).

The present study was expected to show a stronger effect of $\mathrm{ABH}$ on ADD and ARI since prevalence of these illnesses is higher in Colombia than in more developed countries. Since at most of the intervention centers $\mathrm{ABH}$ substituted HSW and the frequency of use was equal to or greater than HSW in controls, the expectation was that $\mathrm{ABH}$ effectiveness would be similar to that found for HSW in the international literature. This seems to be the case, as a Cochrane evidence review of randomized trials on hand washing interventions found that HSW is efficacious in reducing diarrheal episodes by about $30 \%$ in educational and community settings in developed and developing countries (36). Other reviews have also reported a protective effect of HSW combined with HH education for respiratory infections, although of a lesser magnitude and with weaker evidence than that of ADD (35).

Time-dependent risk differences attributable to $\mathrm{ABH}$ use in the present study may have several explanations. First, qualitative information regarding teachers' $\mathrm{HH}$ practices suggests there

\footnotetext{
5 For the purpose of comparing studies, it is important to note that hazard ratios are good numerical approximations of relative risk; for most applications the hazard ratios are within $5 \%$ of their companion relative risks (32).
} 
was a time lag before teachers began to use $\mathrm{ABH}$ and a learning curve for proper use. This is supported by an observed rising trend in the number of gel applications per child from the start to the end of the trial. A dose-response relationship between $\mathrm{ABH}$ and reduction in rates of ADD and ARI has been reported by other studies (16). In addition, two seasonal peaks of ARI in the first and third trimester combined with more frequent use of $\mathrm{ABH}$ at the end of the trial could result in a larger effect (36).

\section{Study limitations}

This study has several limitations. Lack of blinding could have predisposed teachers in the intervention arm to minimize case reports to conform to researcher expectations. Although underreporting by teachers in both arms was detected during supervision, frequency was not quantified; therefore, if the outcome measurement was affected by a differential misclassification, it is plausible that there may be an overestimation of the true effect of $\mathrm{ABH}$ availability on preventing ADD and ARI.

Second, awareness of being observed could alter hand washing practices of control centers, improving the outcomes rates for this arm. However, the teacher survey suggested that there was no change in control arm practices. Furthermore, had there been a Hawthorne effect in either arm, it would have likely occurred at the beginning of the trial, but it is unlikely that this phenomenon would persist during later implementation, which is precisely when the results indicate a favorable impact of the intervention.

On the other hand, the observed level of effectiveness might not be replicated in the day-to-day world or in a larger scale implementation of the intervention, given that the intervention arm's compliance in this trial could have been artificially high as a result of intense follow-up and guaranteed availability of ABH. Also, the results could be less applicable in settings where there is high prevalence of causal agents of ADD and ARI resistant to $\mathrm{ABH}$, such as Norovirus (37-40).

\section{Conclusions}

$\mathrm{ABH}$ may be considered an option in national public health policies for preventing ADD and ARI. On the one hand, $\mathrm{ABH}$ are cheap: at a local cost of as low as US\$ 0.002 per application (37) plus the dispenser, use of $\mathrm{ABH}$ during a 210-day school-year could be US\$ 2.50 per child. ${ }^{6}$ On the other hand, perceived convenience and satisfaction with $\mathrm{ABH}$ reported by teachers in this study indicate that $\mathrm{ABH}$ may have an advantage over HSW in terms of facilitating optimal $\mathrm{HH}$ behavior, which is in line with study findings that have evaluated user perceptions of $\mathrm{ABH}$ and $\mathrm{HH}$ behavior change among schools and hospitals in developing countries $(14,41)$. ABH can be a transitory solution in settings with scarce or inconsistent water supply and/ or a lack of adequate sanitary facilities.

The potential role of $\mathrm{ABH}$ as a public health tool may be further understood by studies that explore cost-effectiveness when compared to other $\mathrm{HH}$ options, factors influencing the adoption of $\mathrm{HH}$ procedures in different settings and among diverse cultural contexts, and effective ways to facilitate long-term behavior change.

Acknowledgements. This work was supported by a grant from the Global Development Network (New Delhi, India), "Fifth Global Research Project: Promoting Innovative Programs from the Developing World: Towards Realizing the Health MDG's in Africa and Asia," and the Bill and Melinda Gates Foundation (Seattle, Washington, United States). We acknowledge the support of

\footnotetext{
6 Based on a median of 5 applications per day and a cost of US\$ 1.40 per dispenser for 14 children, according to the study's consumption data.
}

"Fundación Hogar Integral" (FHI) (Bogotá, Colombia), Instituto Colombiano de Bienestar Familiar (ICBF) (Bogotá, Colombia) and Secretaría Distrital de Integración Social (Bogotá, Colombia). We also thank teachers and parents of each childcare center; our field supervisor, Yohanna Pantoja; and all the fieldwork team members who contributed to a successful trial implementation. We are grateful to Nancy Qian, who provided methodological support on behalf of Global Development Network (GDN); to GDN workshop participants, who contributed with valuable comments and suggestions; to Thomas Sandora and Elaine Larson, who provided hand hygiene survey instruments; to Santiago Ucros and the Javeriana University Clinical Epidemiology Department (Bogotá, Colombia) for their advice on case definitions; and, to Leslee Roberts who provided pretrial estimates of ICC. We also wish to recognize Govi Ltda. (Bogotá, Colombia), the local representative of GOJO Industries Inc. (Akron, Ohio, United States of America), which donated the product for the pilot study and provided dispensers and dispenser installations free of charge.

Authors' contributions. JCC co-directed the study, participated in the conception and design of the study, analysis and interpretation of data and was responsible for overall project management. DP codirected the study, participated in the conception and design of the study, analysis and interpretation of the data, and led the drafting and critical revision of the manuscript. LAS managed the study fieldwork and participated in analysis and interpretation of the data. JCC participated in the conception and design of the study. JQ participated in the design of the study and in data collection. All authors contributed to drafting the manuscript and reviewed and approved the final version. Authors declare to have no conflicts of interest. JCC and DP will act as guarantors.

\section{REFERENCES}

1. World Health Organization. The world health report 2007: a safer future: global public health security in the 21st century. Available from: http://www.who.int/whr/ 2007/en/index.html Accessed 15 July 2009.
2. World Health Organization. Revised global burden of disease (GBD) 2002 estimates: Incidence, prevalence, mortality, YLL, YLD and DALYs by sex, cause and region, estimates for 2002. In: World Health Report 2004. Avail- able from: http://www.who.int/healthinfo/ bodgbd2002revised/en/index.html Accessed 16 May 2007.

3. Acosta-Ramírez N, Peñaloza RE, RodríguezGarcía J. Carga de enfermedad Colombia 
2005: Resultados alcanzados. Bogotá, Colombia: Pontificia Universidad Javeriana, Centro de Proyectos para el Desarrollo; 2005.

4. UN Millennium Project 2005, Lenton R, Wright AM, Lewis K. Health, dignity, and development: what will it take? London; Sterling, VA: Earthscan; 2005. Available from: http:/ / www.unmillenniumproject.org/ documents/WaterComplete-lowres.pdf Accessed 12 December 2008.

5. Bloomfield SF, Aiello AE, Cookson B, O'Boyle C, Larson EL. The effectiveness of hand hygiene procedures in reducing the risks of infections in home and community settings including handwashing and alcoholbased hand sanitizers. Am J Infec Control. 2007;35(10):S27-64.

6. Boyce JM, Pittet D, Healthcare Infection Control Practices Advisory Committee, HICPAC/ SHEA/APIC/IDSA Hand Hygiene Task Force Guideline for hand hygiene in healthcare settings Recommendations of the Healthcare Infection Control Practices Advisory Committee and the HICPAC/SHEA/APIC/ IDSA Hand Hygiene Task Force. MMWR Recomm Rep. 2002;51(RR-16):1-45. Available from: http://www.cdc.gov/mmwr/PDF/rr/ rr5116.pdf Accessed 20 December 2008.

7. Larson E. A causal link between handwashing and risk of infection? Examination of the evidence. Infect Control. 1988 Jan;9(1):28-36.

8. International Bank for Reconstruction and Development/World Bank, Bank-Netherlands Water Partnership, Water and Sanitation Program. Hand washing manual: A guide for developing a hygiene promotion program to increase handwashing with soap. Available from: http://go.worldbank.org/PJTS4A53C0 Accessed 16 May 2007.

9. United Nations Development Program. Human development report 2006. Beyond scarcity: power, poverty and the global water crisis. Basingstoke, New York: Palgrave Macmillan; 2006. Available from: http://hdr. undp.org/en/media/HDR06-complete.pdf Accessed 19 September 2011.

10. World Health Organization, UNICEF, WHO/UNICEF Joint Water Supply and Sanitation Monitoring Programme. Progress on sanitation and drinking water 2010 update. Geneva; New York: World Health Organization; UNICEF; 2010. Available from: http://public.eblib.com/ EBLPublic/PublicView.do?ptiID=538064 Accessed 19 September 2011.

11. Lopez-Quintero C, Freeman P, Neumark Y. Hand washing among school children in Bogota, Colombia. Am J Public Health. 2009;99(1):94-101.

12. Pittet D. Compliance with hand disinfection and its impact on hospital-acquired infections. J Hosp Infect. 2001;48(Aug)(Suppl A):S40-6.

13. Larson EL, Lin SX, Gomez-Pichardo C, DellaLatta P. Effect of antibacterial home cleaning and handwashing products on infectious disease symptoms: a randomized, double-blind trial. Ann Intern Med. 2004;140(5):321-9.
14. Pickering AJ, Boehm AB, Mwanjali M, Davis J. Efficacy of waterless hand hygiene compared with handwashing with soap: a field study in Dar es Salaam, Tanzania. Am J Trop Med Hyg. 2010;82(2):270-8.

15. Luby SP, Kadir MA, Yushuf Sharker MA Yeasmin F, Unicomb L, Sirajul Islam M. A community-randomised controlled trial promoting waterless hand sanitizer and handwashing with soap, Dhaka, Bangladesh. Trop Med Int Health. 2010;15(12):1508-16.

16. Sandora TJ, Taveras EM, Shih M-C, Resnick EA, Lee GM, Ross-Degnan D, et al. A randomized, controlled trial of a multifaceted intervention including alcohol-based hand sanitizer and hand-hygiene education to reduce illness transmission in the home. Pediatrics. 2005;116(3):587-94.

17. California State Department of Education Techniques for preventing the spread of infectious diseases. Sacramento: California State Department of Education; 1983.

18. Geiger BF, Artz L, Petri CJ, Winnail SD, Mason JW. Fun with handwashing education. Birmingham: University of Alabama; 2000.

19. Roberts A, Pareja R, Shaw W, Boyd B, Booth E, Mata JI. A tool box for building health communication capacity. Available from: http://www.globalhealthcommunica tion.org/tools/29 Accessed 10 October 2007.

20. Stark P. Handwashing technique. Instructor's packet. Learning activity package. Sacramento: California State Department of Education; 1982

21. Roberts L, Jorm L, Patel M, Smith W, Douglas RM, McGilchrist C. Effect of infection control measures on the frequency of diarrheal episodes in childcare: A randomized, controlled trial. Pediatrics. 2000;105(4):743-6.

22. Roberts L, Smith W, Jorm L, Patel M, Douglas RM, McGilchrist C. Effect of infection control measures on the frequency of upper respiratory infection in childcare: a randomized, controlled trial. Pediatrics. 2000; 105(4):738-42.

23. Killip S, Mahfoud Z, Pearce K, Killip S, Mahfoud Z, Pearce K. What is an intracluster correlation coefficient? Crucial concepts for primary care researchers. Ann Fam Med. 2004;2(3):204-8.

24. McGraw KO, Wong SP. Forming inferences about some intraclass correlation coefficients. Psychol Methods. 1996;1(1):30-46.

25. Shrout PE, Fleiss JL. Intraclass correlations: Uses in assessing rater reliability. Psychological Bulletin Does not appear in NLM usually name is referenced in full. 1979;86(2):420-8.

26. StataCorp LP. Loneway Large one-way ANOVA, random effects, and reliability. Stata Base Reference Manual I-P: Release 10. College Station,Texas, United States of America: StataCorp; 2007. Pp. 194-9.

27. Grove GL, Zerweck CR, Heilman JM, Pyrek JD. Methods for evaluating changes in skin condition due to the effects of antimicrobial hand cleansers: two studies comparing a new waterless chlorhexidine gluconate/ethanolemollient antiseptic preparation with a con- ventional water-applied product. Am J Infect Control. 2001;29(6):361-9.

28. Clayton DG, Cuzick J. Multivariate generalizations of the proportional hazard models (with discussion). J R Stat Soc Ser A. 1985;148:82-117.

29. Cleves MA, Gould WW, Gutierrez RG. An introduction to survival analysis using Stata, Revised Edition. College Station, Texas, United States of America: StataCorp Press, 2004

30. Kelly PJ, Lim LL-Y. Survival Analysis for recurrent event data: an application to childhood infectious diseases. Stat Med. 2000; 19:13-33.

31. Moulton LH, Dibley MJ. Multivariate time-toevent models for studies of recurrent childhood diseases. Int J Epidemiol. 1997;26:1334-9.

32. Nielsen GG, Gill RD, Andersen PK, Sorensen TI. A counting process approach to maximum likelihood estimation in frailty models. Scand J Stat. 1992;19:25-43.

33. Wintrebert CMA. Statistical modelling of repeated and multivariate survival data. Leiden: Leiden University Medical Center; 2007.

34. Symons MJ, Moore DT. Hazard rate ratio and prospective epidemiological studies. J Clin Epidemiol. 2002;55(9):893-9.

35. Aiello AE, Coulborn RM, Perez V, Larson EL. Effect of Hand Hygiene on Infectious Disease Risk in the Community Setting: A Meta-Analysis. Am J Public Health. 2008;98(8):1372-81.

36. Ejemot R, Ehiri J, Meremikwu M, Critchley $\mathrm{J}$. Hand washing for preventing diarrhoea. Cochrane Database Syst Rev. 2008-23(1) CD004265

37. Glass RI, Parashar UD, Estes MK. Norovirus gastroenteritis. N Engl J Med. 2009; 361(18):1776-85.

38. Liu P, Yuen Y, Hsiao H-M, Jaykus L-A, Moe C. Effectiveness of liquid soap and hand sanitizer against Norwalk virus on contaminated hands. Appl Environ Microbiol. 2010;76(2):394-9.

39. Macinga DR, Sattar SA, Jaykus L-A, Arbogast JW. Improved inactivation of nonenveloped enteric viruses and their surrogates by a novel alcohol-based hand sanitizer. Appl Environ Microbiol. 2008;74(16):5047-52.

40. Okunishi J, Okamoto K, Nishihara Y, Tsujitani $\mathrm{K}$, Miura T, Matsuse H, et al. Investigation of in vitro and in vivo efficacy of a novel alcohol based Handrub, MR06B7. Yakugaku Zasshi. 2010;130(5):747-54

41. Allegranzi B, Sax H, Bengaly L, Richet $\mathrm{H}$, Minta DK, Chraiti MN, et al. Successful implementation of the World Health Organization Hand Hygiene Improvement Strategy in a referral hospital in Mali, Africa. Infect Control Hosp Epidemiol. 2010;31(2):133-41.

Manuscript received on 2 June 2011. Revised version accepted for publication on 28 December 2011. 
RESUMEN Objetivo. Evaluar la eficacia del uso de antisépticos para las manos a base de alcohol en la disminución de las enfermedades diarreicas agudas y las infecciones respiratorias agudas en niños de 1 a 5 años de edad en los centros de atención infantil

Ensayo controlado aleatorizado por conglomerados sobre el uso de antisépticos para las manos para la prevención de enfermedades infecciosas en los niños en Colombia donde el lavado de las manos con agua y jabón no es factible.

Métodos. El presente fue el primer ensayo controlado y aleatorizado por conglomerados llevado a cabo en un país en desarrollo. El estudio tuvo lugar en 42 centros de atención infantil con disponibilidad de agua esporádica y limitada ubicados en seis ciudades de Colombia. Se asignó aleatoriamente a los participantes a usar antisépticos a base de alcohol como complemento del lavado de las manos (grupo de intervención: 21 centros/794 niños) o a continuar llevando a cabo las prácticas de lavado de las manos habituales (grupo de referencia: 21 centros/933 niños). Los casos de enfermedades diarreicas agudas e infecciones respiratorias agudas fueron identificados mediante la notificación de los signos y síntomas de enfermedad por los maestros. Se efectuó un seguimiento de los acontecimientos adversos. Se obtuvieron las razones de riesgos instantáneos (HR) usando modelos de regresión multivariante de riesgos proporcionales de Cox con fragilidad compartida.

Resultados. Se alcanzó un total de 336038 niño-días de vigilancia. La pérdida de contacto durante el seguimiento fue de 14,5\%. Durante el primer trimestre del estudio no hubo diferencias en las razones de riesgo para las enfermedades diarreicas agudas ni para las infecciones respiratorias agudas. En el segundo y tercer trimestres se encontraron disminuciones significativas del riesgo de enfermedades diarreicas agudas en el grupo de intervención en comparación con el grupo de referencia $(\mathrm{HR}=0,55$, $P<0,001$ y $\mathrm{HR}=0,44, P<0,001$, respectivamente). Para las infecciones respiratorias agudas se observaron disminuciones significativas del riesgo durante el segundo trimestre ( $\mathrm{HR}=0,80, P<0,05)$ y el tercer trimestre $(\mathrm{HR}=0,69, P<0,001)$ del ensayo. No ocurrieron eventos adversos.

Conclusiones. Los antisépticos para las manos a base de alcohol son eficaces para prevenir las enfermedades diarreicas agudas y las infecciones respiratorias agudas y son seguros. Las políticas nacionales de salud pública de Colombia para la prevención de estas enfermedades deben incluir su uso, especialmente en los ámbitos donde el lavado de las manos con agua y jabón está limitado por la disponibilidad de agua.

Palabras clave

Lavado de manos; antiinfecciosos locales; enfermedades gastrointestinales; infecciones del sistema respiratorio; diarrea; etanol; preescolar; países en desarrollo; ensayos clínicos controlados aleatorios como asunto; Colombia. 